\section{SOI: 1.1/TAS DOI: 10.15863/TAS International Scientific Journal Theoretical \& Applied Science}

p-ISSN: 2308-4944 (print)

e-ISSN: 2409-0085 (online)

Year: 2016

Issue: 3

Volume: 35

Published: 30.03 .2016

http://T-Science.org
Jamshid Sharafetdinovich Tukhtabaev

senior scientific researcher - applicant

(Ph.D student),

Samarkand state university jamshidstuzum@mail.ru

SECTION 19. Management. Marketing. Public administration.

\title{
THE THEORETICAL APPROACH ON INCREASE OF PROFESSIONAL SKILL OF WORKERS AND STIMULATION OF THEIR CREATIVITY
}

Abstract: In the article theoretical investigated the concept of professional skill, a way of increase of its', roles and urgencies in innovative activity in the enterprise. The is determined reproductive and creative kind of activity of the person and interrelation to stimulation of effective labour. Also by, it proved urgency of increase of professional skill of workers for development of the highly skilled and competitive personnel.

Key words: professional skill, motivation, stimulation, efficiency of labour, productivity of labour, the creative activity, qualified of personal, training, the human capital.

Language: English

Citation: Tukhtabaev JS (2016) THE THEORETICAL APPROACH ON INCREASE OF PROFESSIONAL SKILL OF WORKERS AND STIMULATION OF THEIR CREATIVITY. ISJ Theoretical \& Applied Science, 03 (35): 45-48.
Soi: http://s-o-i.org/1.1/TAS-03-35-8
Doi: crossef http://dx.doi.org/10.15863/TAS.2016.03.35.8

The concept of professional skill characterizes a high degree of development by workers of their trade as on a level of shown knowledge of theoretical bases, and on skill to put them into practice. Professional skill as the qualifying characteristic of the worker is used by some enterprises as the basis for an establishment of surcharges to a tariff level of its wages. As the basic criterion at an establishment of surcharges for professional skill faultless quality of production or services serves. The circle of workers, marked professional skill and having the right on corresponding the additive to the salary, includes working 3-6 categories. As to heads, experts and other employees, their material encouragement it is carried out on system of awarding «for high achievements in labour» in size from 50 up to 100 percent and is higher from the official salary.

Thus, despite of different concepts (professional skill of workers and high achievements in labour of employees), is actually supposed encouragement workers for performance of the duties stipulated by the labour contract, the working order or the duty regulations. In fact, qualitative production for the worker or qualitative performance of official duties for the employee is their norm of labour [1, p. 138]. Therefore, such system encouragement hardly can be considered effective for the employer, which for the same results of labour of the worker pays twice, and for the worker it does not give those guarantees of stability, which are inherent in the salary under the tariff. At such position the idea on that instead of payment bonus for "achievements", entering in a circle of duties of the worker, to turn liberated means for increase tariff rates and official salaries to workers, that will positively influence motivation of labour effective.

At the same time it is necessary to encourage in every possible way creative development and initiative offers of experts and workers - innovators within the framework of programs of scientifictechnical and social-economic development of the enterprise, and also by way of expansion or overlapping of the labour functions, which have been not stipulated labour by the contract. At a determining role of material stimulus to creative activity it is necessary to take into account constant aspiration of the person to self-affirmation as person that promoted to no small degree by development and realization of labour and creative potential of workers, From this point of view (as the general qualifying characteristic, and, not only the worker, but also the expert, the head) it is possible to consider professional as a necessary condition of success of the decision of the creative tasks connected to innovative activity of the enterprise.

At definition of motives of innovative activity as creative strategy of the enterprise the reasons of instability existing the positions dependent both from 
the enterprise, and from a market situation. With this purpose it is necessary to define: whether can create the enterprise new production and use for this purpose available resources; whether competitors can create production, the best on quality, and what prognosticate strategy of their behaviour [2, p. 155]. The answer to these questions define a choice new spheres activity of the enterprise. Depending on an overall objective of an innovation the priority orientation of an innovation - it can be the capital savings, technical (new product), technological, labour - savings, a material - savings, organizational, information, industrial, social.

Proceeding from the accepted strategy of realization of creative ideas and directions of innovative activity solve questions of structure of the enterprise and maintenance of a favorable climate for realization of innovations, concrete actions which are specified during their realization. The best results in use of creative potential of workers are achieved under condition of close interaction of scientists, experts and practiced on the basis of connection of scientific creativity with technical and other kinds of creativity. The decision of this task assumes integration of all creative power within the framework of the uniform innovative process oriented on end results. It allows to essentially increase efficiency of creativity, to create conditions at which recognized useful to an innovation would be realized in practice.

It is essentially important, that in structure of human activity always it is possible to allocate two essential the moment - reproduction of the achieved results, on the one hand, and change of these results on higher basis, with another. Thus reproducing (reproductive) and changing (creative) kinds of activity of the person are interconnected and mutually conditioned. The measure of a ratio and distinction of these two components of labour activity - reproductive and creative - characterizes creative potential of the person and a society. At definition of this measure are usually limited to the attitude of expenses of time for creative and not creative parts of work. Meanwhile it is not less important to take into account creative complexity of work and a qualifying level of the worker. On the basis of precise differentiation of reproductive and creative processes of labour it is possible to draw a conclusion that for them various approaches to stimulation of effective labour.

Reproductive labour, by definition, assumes qualitative reproduction of each unit of the mastered production, meeting the requirements of a competitive consumer demand. In this case, at reflection of the specified requirements in the labour task, there is no necessity for any additional stimulation to working tariff conditions. At the same time should be encouraged reduction in the specific charge of raw-material, materials, fuel and energy on a unit of production [3, p. 118].

Concentrated enough creative activity of researchers and developers on this or that site assumes search and realization of new decisions in this connection its stimulation can be carried out on the contract basis providing the size and the order of payment of compensation on intermediate and end results of work. Separate elements of creativity are to some extent inherent in heads, experts and the workers, even occupied in sphere of reproductive labour, that should be stimulated with corresponding surcharges to tariff rates and salaries of workers. Such position is distributed, in particular, to all workers who combine the labour functions with administrative functions, participate in discussion and decision-making on work of the enterprise and own actions of the enterprise. In these conditions the favorable environment for increase of interest of each worker in expansion of a circle of duties, in display of the initiative, in is contributing of realization of innovations.

Increase of professional skill of workers and training to their methods of creativity demand development of systems of the further education in view of formation of new specialities in the field of management, marketing, economy and sociology of labour, technology of creativity etc. In particular efficiency of labour of the manager in many respects depends on a degree of possession of him the certain organizational skills, from skill in managerial process and manuals of people. Organizational skills of the manager serve as a subject of studying of psychological sciences and theories of management. For example, for development of organizational skills in managers in Slovakia develop the programs of their training based on creation of models of communication samples, the most typical for management activity [4, p. 76], in view of which three allocate phases of training. In the first there is an strengthening of elements of self-affirmation, self-confidence of the manager, in the second defined properties of group and its ability, in the third - such skills, as settling of conflicts and conflict situations.

Increase of professional skill of any categories of the personnel consists in development and realization of programs of training of workers with a view of maintenance of the current and prognosticate needs of the enterprise in qualified personnel. Training of the personnel is required in those cases when: the worker comes on the enterprise; the worker appoint to a new post or charge to him new work; the worker does not have not enough skills for work, and also when there are serious changes in economy of the enterprise or in an environment.

The basic requirements providing efficiency of programs of training, consist in the following [5, p. 43]: 
1. Full and authentic knowledge of workers of the enterprise of possible forms of training, of communication of this training with their professional status, material maintenance.

2. A climate at the enterprise, favorable to aspiration of workers to training. It means encouragement of pupils, good conditions for employment, a duly estimation of results of training.

3. A rational combination of theoretical and practical training.

Purposeful vocational training of workers is the basic source of increase of their labour and creative potential for the successful decision of tasks of the enterprise. Thus expenses for training should be considered as one of forms of investments. From expansion of investments into the human capital win both the enterprises, and trained workers. Businessmen win, receiving a high quality manpower, and workers win not only from prospect of service promotion and from increase of wages, but also from increase of competitiveness on a labour market which is provided with education.

In this connection it is necessary to note concrete sense of concept the human capital as economic category. In textbook Erenberg and Smith $[6$, p. 112] it is marked, that the general riches the USA in 1991 year estimated approximately in 54,5 bln. doll., from which 26 bln. doll. or 48 percent at the human capital, including saved up investments in such spheres of activity as education, vocational training and migration, whereas the material capital includes public stocks as the ground, buildings and the equipment.

Reproduction of the human capital assumes dynamical development of the general and special education on the basis of last achievements of a science and technologies, and it demands corresponding means both from budgetary, and in a growing measure from unbudgetary sources. Any services including educational, cannot be free-ofcharge, speech can go only about the form and sources of compensation of their cost both for a society, and for private persons. The knowledge got in educational process, form base for their subsequent accumulation and practical use [7, p. 65]. Therefore educational the cycle can be considered completed only under condition of mastering by its participants not only as theoretical knowledge, let even at the advanced scientific level, but also necessary toolkit, practical skills, methods and technologies of their use. In this connection at definition of qualifying requirements to any categories of workers it is necessary to establish not only, that the worker should know, but also be able (till now, by tradition, it is done only concerning workers).

The estimation of efficiency of functioning of this or that educational system can be based only on the comparative analysis of expenses for purchase of knowledge and results of their practical use.

By consideration of a question on investments into vocational training the American experts allocate two types of the training: general training, which promotes increase of labour productivity of the worker equally at many enterprises, and special training which promotes increase of productivity of labour worker on the concrete enterprise. The general training can include, for example, in case of preparation of secretaries, typewriting or work with text editors on a computer. Purpose of special curriculums can be development of work by the machine, which is in operation in an individual copy in firm, or acquaintance with the organization of process of manufacture in firm. The majority of kinds of vocational training carries in itself of attributes both types.

At hiring workers the firm follows the general course of their vocational training and carries the pure costs connected to it in an initial stage therefore productivity grows and accordingly the wages increase also within the limits of the achieved increase in incomes. But if trained the worker can expect for higher salary in other firm which has not carried expenses for his training, he to not apply to take advantage of this opportunity. Therefore firms can be interested to carry expenses on the general vocational training only in case employed workers undertake to fulfil the certain number of years in the given firm or otherwise to pay expenses for their training.

If the worker pass special a curriculum, due to what his limiting productivity (on another, profitableness of labour) during the subsequent period at the same enterprise achieves higher level, it does not affect a limiting product trained in other firms which remains at a former level. Thus, the greatest, on what this worker in other firms can expect, makes the wages equal to limiting productivity of labour, not taking place special vocational training. At the same time incentive motive for firm to carry spend special training the workers that there is an opportunity to pay in it during the subsequent period the wages exceeding her size before training is, but is lower than after training. Thus it is recommended in mutual interests of workers and the employer to provide long-term cooperation, and it can be in the best way achieved by division of time of costs into training in an initial stage. However, in conditions of an economic crisis workers of the enterprises hardly in a condition to pay the vocational training. For this purpose can be on the certain conditions in part means from funds of education (are used concerning the general training and funds of employment concerning special training).

In the textbook of academician K.H.Abdurahmanov estimations human resources as are considered: worker force, labour resource, labour 
potential, human factors and the human capital $[8, \mathrm{p}$. 55]. The human capital can be divided into two parts wasteful and utility [9, p. 348]. The first parts offer the account of expenses for the human capital (by analogy to a fixed capital) and its amortization. The second parts suggest to estimate directly effect of those or other personnel investments. At the first approach of an expense for the human capital are taken into account or as the long-term investments increasing the size of this capital, or are written off as loss. Expenses for training are considered by analogy to expenses for repair of the equipment as restoration of initial cost of the capital, or as addition of cost of the human capital by analogy to expenses for modernization of the equipment. Doubtful analogies to normal term of amortization, deoxidizing and balance cost by virtue of the various nature of compared categories of the capital are represented. From this point of view prof. B.M.Genkin, that depending on expenses it is essentially impossible to measure change of the human capital with the same accuracy, as for the equipment [10, p. 205]. As to utility with its help it is offered to estimate economic consequences of programs of development of the personnel, proceeding from duration of influence of the program on labour productivity and other factors of productivity of labour, quantity of the trained workers, a cost estimation of distinctions in productivity of labour of the best and average workers, effect of training of workers (a share from the general growth of productivity), expenses for training of one worker. In our opinion, the offered approach is worthy as the approached method of definition of efficiency of programs of training of workers. At the same time it is represented more natural to use a method based on comparison of expenses for training of the worker with an increment of his earnings (the income of the enterprise) after training. Thus the today's estimation of the future benefits is determined by the sum of members of a decreasing geometrical progression during the predicted period of use of the received knowledge, i.e. attitudes of expected increase in earnings in each year to the sum of unit and the market interest rate on the capital in a degree corresponding to the same year. Than less interest rate and the more expected gain of earnings and number of years of work, the more effectively the investment into improvement of professional skill.

\section{References:}

1. Genkin BM (1998) "Economy and sociology of labour". The textbook. - Moscow: "NORM", 1998. - pp. 138.

2. Travin VV (1992) "Motivation of labour and management". Moscow: "Business", 1992. - pp. 155.

3. Germanova OE (1996) "Productivit: the economic contents and problems of measurement". Moscow: "Science", 1996. - pp. 118.

4. Slezenger GE (1997) "Organization of labour the factor of qualitative improvement of activity and prosperity of the enterprises and firms (on materials of the International colloquium)". Moscow: "Labour abroad”, № 2, 1997. - pp. 76.

5. (1997) The adviser of director: Magazine for the chief. Moscow: "INFRA-M", 1997. (Periodical journal), № 3. - pp. 43.
6. Erenberg RD, Smith RS (1996) "Modern economy of labour. The theory and a state policy". Trans. from English. Moscow: "MSU", 1996. - pp. 112.

7. Artykov AA, Zokirova NK, Abdurahmanov OK (2008) "Human the capital in conditions of reforming and modernization of economy". The monography. T.: "The science and technology", 2008. - pp. 65.

8. Abdurahmanov KH (2012) "Developments of the person". The textbook. T.: "Economy", 2012. - pp. 55.

9. Odegov YG (2005) "Management the personnel in structurally - logic circuits". Moscow: "The academic project", 2005. - pp. 348.

10. Genkin BM (2007) "Economy and sociology of labour". The textbook. Moscow: "NORM", 2007. - pp. 205. 